\title{
Toxicity of interferon
}

\author{
G M SCOTT, D S SECHER, D FLOWERS, J BATE, K CANTELL, D A J TYRRELL
}

\begin{abstract}
The effects of partially purified human leucocyte interferon (PIF) and of a preparation purified by passage twice through a monoclonal antibody affinity chromatography column (NK2IF) were compared with those of a control solution in healthy volunteers. After intramuscular injections both interferon preparations caused rises in pulse rate and body temperature, changes in circulating white cell counts, and various unpleasant symptoms, the most common of which were headache, malaise, and fever. Slightly lower doses of NK2IF were given, and this was reflected in lower peak serum concentrations. Mean symptom scores, however, were not lower after NK2IF than after PIF. Local inflammatory reactions eight hours after intradermal inoculations of these interferons were similar.

Purification of interferon using a monoclonal antibody does not reduce the facets of its activity considered in this study. They are therefore inherent in the leucocyte interferon type selected by the antibody.
\end{abstract}

\section{Introduction}

Interferons have potential therapeutic applications in viral infections ${ }^{1}$ and cancer. ${ }^{2}$ Relatively large doses are required for detectable antiviral effects. ${ }^{1}$ In such doses interferons cause

\footnotetext{
Division of Communicable Diseases, Clinical Research Centre, and Haematology Department, Northwick Park Hospital, Harrow, Middlesex HA1 3UJ

G M SCOTT, MRCP, senior registrar

D FLOWERS, FIMLS, technician

J BATE, FIMLS, senior medical laboratory scientific officer

D A J TYRRELL, FRS, FRCP, deputy director

MRC Laboratory of Molecular Biology, Cambridge D S SECHER, PHD, scientific staff member

Central Public Health Laboratory, Helsinki, Finland K CANTELL, MD, professor of virology
}

influenza-like symptoms and so-called "bone marrow depression" with leucopenia, thrombocytopenia, and anaemia." These effects may limit the dose of interferon which may be given. Karmazyn et al proposed that interferons released during focal viral infections such as influenza may mediate generalised systemic symptoms. ${ }^{4}$ In long-term treatment studies, ${ }^{5}$ however, a change from one preparation of human leucocyte interferon $(\mathrm{HuIFN} \alpha)$ to a purer one resulted in a reduction in symptoms; similarly, inflammatory skin reactions to intradermal interferons were reduced with purer preparations, ${ }^{8}$ suggesting that some of the inflammatory properties might be due to contaminants. To test this hypothesis we investigated the effects of highly purified $\mathrm{HuIFN} \alpha$ in healthy volunteers.

\section{Materials}

Pooled buffy-coat leucocytes were stimulated with Sendai virus and the crude interferon partially purified as described, ${ }^{7}$ giving a solution (PIF) of concentration 9 million reference units $/ \mathrm{ml}(\mathrm{MU} / \mathrm{ml})$ and activity $1.5 \mathrm{MU} / \mathrm{mg}$ protein (approximately $0.3 \%$ pure interferon protein).

Alternatively, pooled crude supernatants $(9.71$, about $50000 \mathrm{U} / \mathrm{ml})$ were passed through a monoclonal antibody affinity column ${ }^{8}$ (NK2Sepharose $4 \mathrm{~B}, 4 \times 1.4 \mathrm{~cm}, 18 \mathrm{ml}$ bed volume). The column was washed successively with $100 \mathrm{ml}$ of $50 \%$ ethylene glycol in phosphatebuffered saline and $50 \mathrm{ml}$ phosphate-buffered saline. The interferon bound to the column was then eluted with $50 \mathrm{ml}$ citric acid $0.1 \mathrm{~mol} / 1$, sodium chloride $0.3 \mathrm{~mol} / 1$. After the addition of human serum albumin ("reprecipitated," Blood Products Laboratory, Elstree, Herts, UK) to $2 \mathrm{mg} / \mathrm{ml}$ and phenol red to $0.02 \mathrm{mg} / \mathrm{ml}$ the solution was neutralised by adding $4 \mathrm{~N}$ sodium hydroxide. The specific activity of the interferon at this stage was estimated to be about $100 \mathrm{MU} / \mathrm{mg}$. This interferon was further purified on a second NK2-Sepharose column $(1.3 \times 4 \mathrm{~cm}, 5 \mathrm{ml}$ bed volume). Analysis of the citric acid eluted material (10 ml, $\left.20 \mathrm{MU} / \mathrm{ml}, 2.5 \times 10^{8} \mathrm{U} / \mathrm{mg}\right)$ by sodium dodecyl sulphate polyacrylamide gel electrophoresis showed a major band at $19000 \mathrm{MW}$ and a minor band at $22500 \mathrm{MW}$. Phenol red, human serum albumin, and sodium hydroxide were added as before and the solution passed through a $\mathbf{0 . 4 5} \mu$ membrane filter (Millipore) that had been prewashed with $20 \%$ human serum albumin and phosphate-buffered saline. The interferon was diluted to a final concentration of $4.6 \mathrm{MU} / \mathrm{ml}$ in phosphate-buffered saline, $2 \mathrm{mg} / \mathrm{ml}$ human serum albumin. This diluent was used as a control.

The preparations were divided into individual dose aliquots and 
coded. Aliquots of each were removed and tested extensively to ensure the absence of adventitious contaminants, particularly residual Sendai virus, and for acute toxicity in guinea-pigs and mice.

\section{Volunteers and method}

The protocol was approved by the ethical committee of Northwick Park Hospital. Volunteers from the hospital and Clinical Research Centre were screened for fitness and their general practitioners informed. Atopic subjects, those with more than one first-degree relative with atopy, and women at risk of pregnancy were not eligible.

Three male and six female volunteers (mean age 37 (range 25-54) years) were given one injection each of the three preparations intramuscularly, each injection separated by four days. They were given according to a random code by a physician who was unaware of the contents of the coded solutions and then had no part in further care of the volunteers, who were told that one injection would be a placebo and that either one or both of the other injections might cause symptoms. Physical observations and blood tests were taken for 24 hours, the volunteers being admitted for overnight stay on each occasion. New symptoms or changes in symptoms were recorded by marking $10 \mathrm{~cm}$ lines according to the degree of severity of the symptoms.

The doses of the interferons given to each volunteer differed slightly. This was because the volume in each phial of NK2IF was slightly less than expected. Whereas we had intended to give $0.25 \mathrm{ml}$ (2.25 MU) PIF and $0.5 \mathrm{ml}(2.3 \mathrm{MU}) \mathrm{NK} 2 \mathrm{IF}$, four volunteers received slightly less NK2IF. The mean dose of PIF given was $1.30 \mathrm{MU} / \mathrm{m}^{2}$ body surface area (range $1 \cdot 14-1 \cdot 43$ ) and of NK2IF was $1.12 \mathrm{MU} / \mathrm{m}^{2}$ (range $0 \cdot 86-1 \cdot 32$ ).

\section{Results}

\section{SYMPTOMS}

None of the volunteers reported symptoms after injections of the control solution. All experienced symptoms after the first and all but one after the second active interferon injections (table).

Incidence of symptoms after injections of interferons (PIF and NK2IF) in nine volunteers

\begin{tabular}{|c|c|c|c|c|c|}
\hline & PIF & NK2IF & & PIF & NK2IF \\
\hline $\begin{array}{l}\text { Headache } \\
\text { Malaise } \\
\text { Fever } \\
\text { Chills } \\
\text { Fatigue } \\
\text { Myalgia } \\
\text { Low backache } \\
\text { Joint pain } \\
\text { Shaking } \\
\text { Nausea } \\
\text { Anorexia }\end{array}$ & $\begin{array}{l}9 \\
8 \\
7 \\
6 \\
6 \\
5 \\
5 \\
3 \\
3 \\
3 \\
2\end{array}$ & $\begin{array}{l}8 \\
7 \\
6 \\
6 \\
6 \\
5 \\
4 \\
5 \\
3 \\
3 \\
3\end{array}$ & $\begin{array}{l}\text { Late injection-site } \\
\text { pain } \\
\text { Eye pain } \\
\text { Confusion } \\
\text { Stiff neck } \\
\text { Urgency of } \\
\text { micturition } \\
\text { Yawning, } \\
\text { somnolence } \\
\text { Vomiting }\end{array}$ & $\begin{array}{l}2 \\
2 \\
2 \\
1 \\
1\end{array}$ & $\begin{array}{l}1 \\
1 \\
3 \\
1\end{array}$ \\
\hline
\end{tabular}

Symptoms were scored out of 100 according to the marks made on $10 \mathrm{~cm}$ lines. Mean maximal symptom scores (the sum of the maximal recorded scores for every symptom divided by the number of symptoms experienced) were calculated; those after NK2IF were higher but not significantly different from those after PIF by paired $t$ test. The scores were higher, however, after the first active injection compared with the second $(p<0.05)$; five out of the nine volunteers received NK2IF first.

The symptoms began about four hours after the injections, were most severe around four hours later, but rarely lasted more than 10 hours. Four volunteers requested paracetamol after PIF and five after NK2IF, all eight or more hours after injections. One volunteer experienced severe nausea and repeated vomiting after NK2IF, which was relieved by prochlorperazine $12.5 \mathrm{mg}$ intramuscularly given 15 hours after interferon.

\section{PHYSICAL SIGNS}

Consistent and appreciable rises in body temperature and pulse rate, maximal at eight hours, returning to normal by 15 hours, occurred in all the volunteers after injections of both PIF and NK2IF compared with the control injections (fig 1). Paracetamol resulted in the rapid resolution of raised temperature. Although distinct changes in systolic and diastolic blood pressure were observed in some volunteers, these were not consistent.
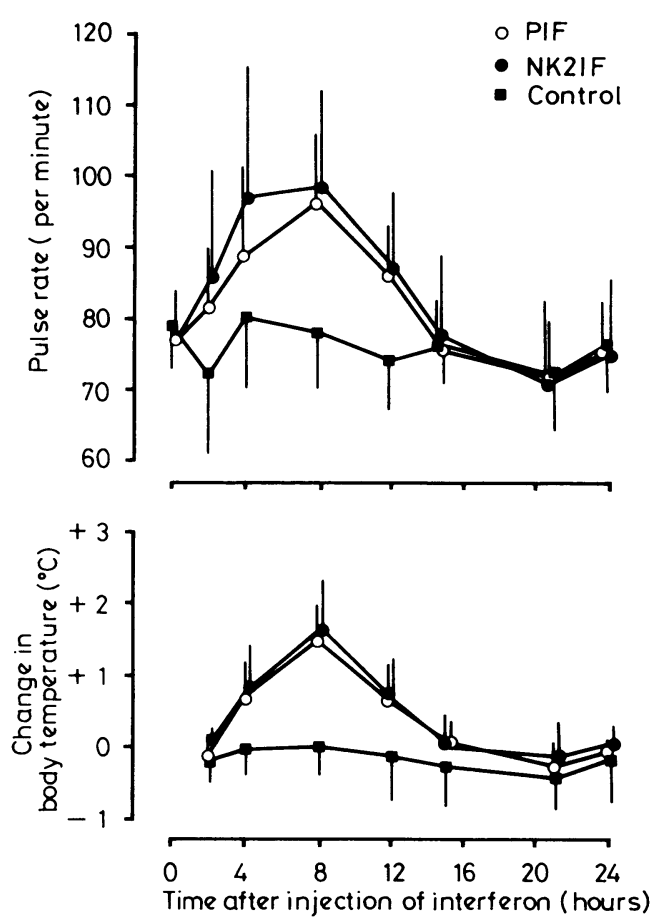

FIG 1-Changes in pulse rates and oral temperatures after injections of interferons and control preparation (means of nine observations $\pm 1 S D$ ).

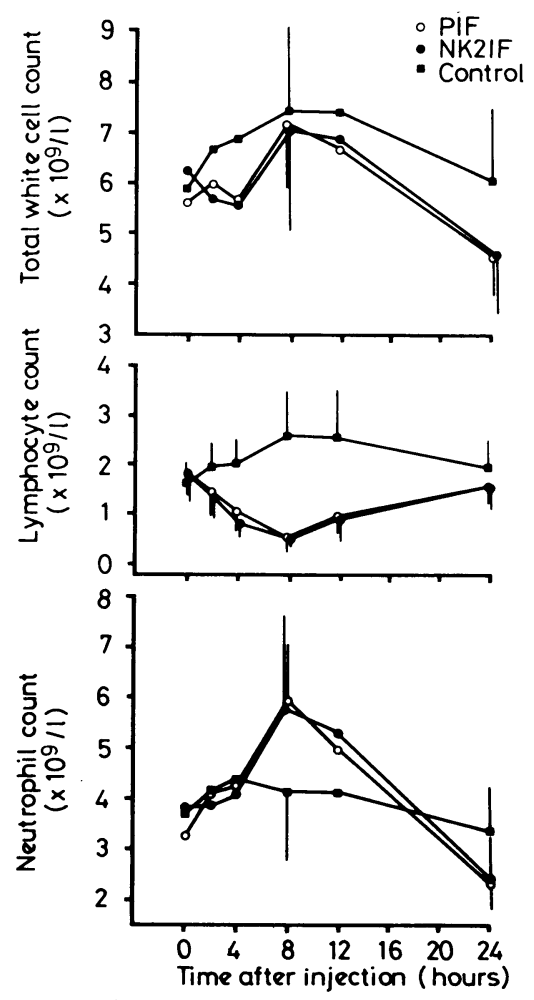

FIG 2-Changes in peripheral total and differential white cell counts (means of nine observations \pm 1SD) after injections of interferons and control preparation.

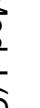




\section{HAEMATOLOGY}

Figure 2 shows the changes that occurred in the total and differential white blood cell counts. Expected diurnal variations were observed after control injections. The neutrophil counts were raised at eight hours and depressed at $\mathbf{2 4}$ hours after interferon injections; the effects were significant by paired $t$ tests at eight hours (control $v$ PIF $p<0.01$; control $v$ NK2IF $p<0.05$ ), but only the response to PIF was significant at 24 hours $(p<0.01)$. Both PIF and NK2IF caused a significant fall in lymphocyte counts $(p<0.001)$, maximal at eight hours and recovering by 24 hours after injections. The total white blood cell counts were not altered by interferons until 24 hours, when they were significantly depressed after injections of both PIF $(p<0.02)$ and NK2IF $(p<0.05)$. There were no significant changes in peripheral monocyte or eosinophil counts, haemoglobin concentrations, or platelet counts.

\section{BIOCHEMISTRY}

Blood tests of renal and hepatic function, cholesterol, and blood glucose performed before and 24 hours after each injection showed no important changes. Urine was examined by microscopy and routine ward testing. The only abnormal findings were a trace of glycosuria $(0.25 \%)$ by Clinitest in the eight- to 12 -hour specimens after injections of NK2IF in two volunteers. Blood glucose concentration was not checked during that period, but multiple random estimations at other times were within normal limits.

\section{INTERFERON PHARMACOKINETICS}

Interferon concentrations were measured in serum by the inhibition of Semliki Forest virus RNA synthesis ${ }^{\circ}$ in embryonic bovine tracheal cells. ${ }^{10}$ These cells are highly sensitive to IFNa, permitting the detection of low titres of interferon, even though normal serum diluted $1: 10$ or $1: 20$ interferes with the assay. The titres shown in figure 3 are expressed in reference units by comparison with an IFN $\alpha$ standard (MRC 69/19B). The $\log _{10}$ peak serum concentrations correlated

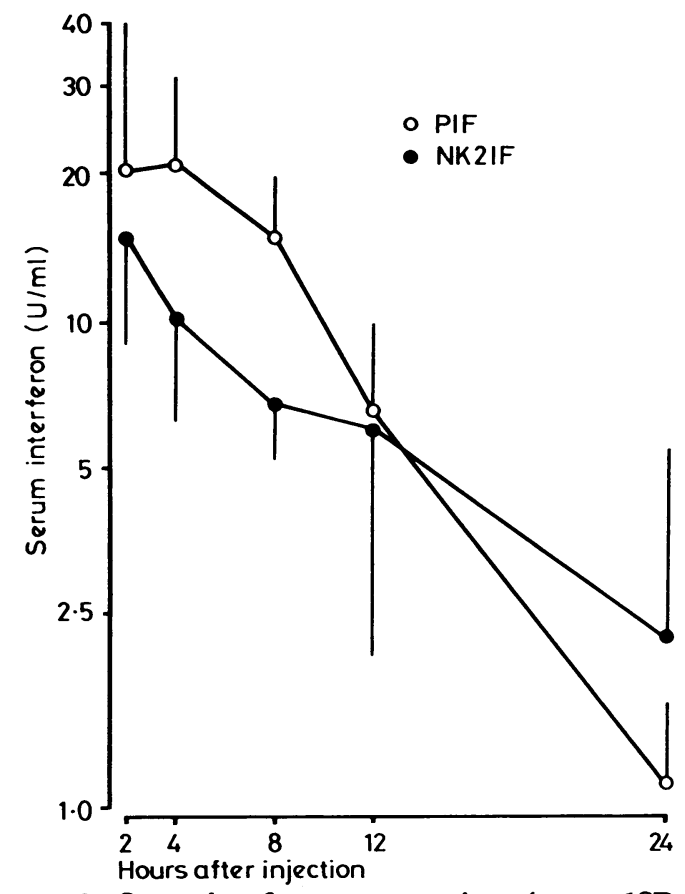

FIG 3-Serum interferon concentrations (mean \pm 1SD calculated on $\log _{10} \mathrm{U} / \mathrm{ml}$ ) |after intramuscular injections of interferons.

directly with the dose given $\left(\mathrm{MU} / \mathrm{m}^{2}\right)(\mathrm{r}=0.63, \mathrm{p}<0.05)$. No interferon was detected in urine collected over 24 hours from the volunteer with the highest serum concentrations.
SRIN REACTION STUDIES

In view of observations ${ }^{6}$ that purification of IFN $\alpha$ by chemical means reduced late (four- to eight-hour) skin reactivity, seven further volunteers received a series of three intradermal injections across the upper back, one each of PIF ( $0.1 \mathrm{ml}$ containing $0.45 \mathrm{MU})$, NK2IF $(0.1 \mathrm{ml}$ containing $0.46 \mathrm{MU})$, and control $(0.1 \mathrm{ml})$. These were given blind in different random order across each back. The lesions were measured and the approximate area calculated as described. ${ }^{6}$

Figure 4 shows the mean lesion sizes observed. Immediate flare reactions were seen, and $t$ tests performed on the $\log _{10}$ transformed mean lesion areas over the first five time points showed significant differences between each solution tested. The reactions became smaller towards the end of an hour and returned with dense, well-circumscribed erythema without swelling, maximal at eight hours.

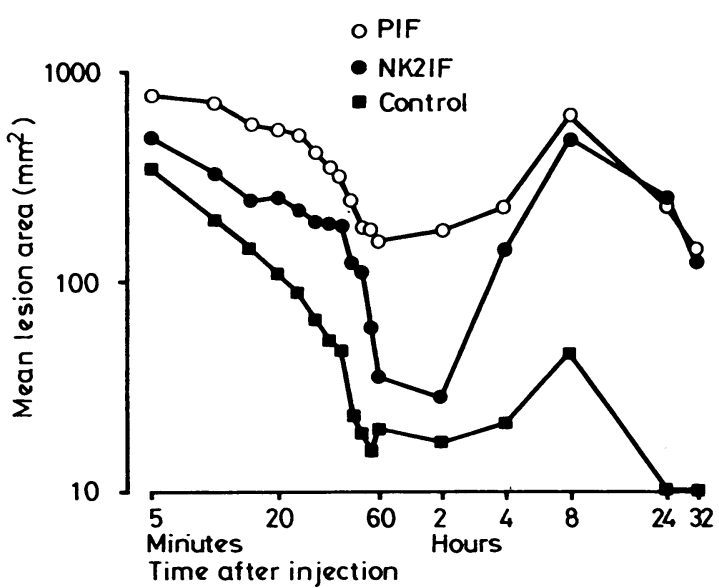

FIG 4-Mean skin reaction sizes after intradermal injections of interferons and control preparation (seven observations).

The sizes of the maximum late reactions after injections of NK2IF and PIF were similar, but both were significantly greater than those after the control injections (paired $t$ tests on $\log _{10}$ transformed maximum lesion sizes, $p<0.001$ ).

The intensities of the late reactions were scored, on a scale from 0 (nil visible) to 3 (very intense erythema), by two independent observers at each time point after one hour. Both interferon preparations caused greater maximal lesion intensities than the control injection (paired $t$ tests on $\sqrt{\mathrm{x}+0.5}$ transformed mean values of two observers' scores; PIF $v$ control $p<0.002$, NK2IF $v$ control $p<0.01$ ).

\section{Discussion}

Despite the administration of a slightly lower mean dose and lower peak serum interferon concentrations, intramuscular NK2IF caused just as many generalised symptoms as PIF. Only one volunteer had no symptoms after a low dose of NK2IF $\left(0.86 \mathrm{MU} / \mathrm{m}^{2}\right)$, but he did have pulse and temperature increases equal to those after PIF (1.24 MU/m²).

The effects of both interferon preparations on pulse rates, body temperatures, and total and differential white blood cell counts were strikingly similar. In a previous study ${ }^{3}$ the total white blood cell count fell soon after injections of lymphoblastoid interferon to a nadir at 12 hours, but the doses of interferon were slightly higher and the subjects tested were not healthy volunteers.

The skin inoculation studies showed no differences between PIF and NK2IF in late (eight-hour) inflammation. A tenfold higher concentration of NK2IF was given intradermally compared with the purest IFN $\alpha$ preparation tested previously, which probably accounts for the larger and more persistent reactions seen in this study. A total dose of $9 \cdot 1 \times 10^{5}$ U IFN $\alpha$ given intradermally caused systemic reactions in five out of seven volunteers. 
Clearly, purification of interferon using a monoclonal antibody did not reduce its toxicity, inflammatory effect, or its effects on peripheral white blood cells.

The effects of the two preparations were so similar that it seems unlikely that remaining contaminants in NK2IF were responsible. This suggests that these properties are inherent in the IFN $\alpha$ type selected by the antibody. The symptoms experienced at these moderate therapeutic doses may not be acceptable in the treatment of trivial conditions.

Two volunteers were each given a further intramuscular injection of NK2IF (2.3 MU) while taking oral indomethacin, $50 \mathrm{mg}$, six hourly. Expected rises in pulse rate and body temperature did not occur. One volunteer had no symptoms while the other had only mild headache and myalgia (mean maximal score 10 compared with 42 when not taking indomethacin). The effects on total and differential white cell counts, however, were not altered by this treatment. Possibly, therefore, symptoms may be reduced by giving prostaglandin antagonists or corticosteroids, but the effects of these drugs on the antiviral and antitumour properties of interferons in vivo have yet to be determined.

We thank Dr T Gordon for administering the interferon; the MRC Committee on Interferon for supporting the study; Dr R S Lane,
Blood Products Laboratory, Elstree, for the gift of human serum albumin; and the volunteers for their wholehearted co-operation.

\section{References}

1 Scott GM, Tyrrell DAJ. Interferon: therapeutic fact or fiction for the eighties? Br Med f 1980;280:1558-62.

2 Sikora K. Does interferon cure cancer? Br Med f 1980;281 :855-8.

3 Priestman TJ. Initial evaluation of human lymphoblastoid interferon in patients with advanced malignant disease. Lancet 1980;ii:113-8.

${ }^{4}$ Karmazyn M, Horrobin DF, Manku MS, et al. Interferon fever. Lancet $1977 ; \mathrm{ii}: 307$.

${ }^{5}$ Ingimarsson S, Cantell K, Strander H. Side effects of long-term treatment with human leukocyte interferon. $\mathcal{F}$ Infect Dis 1979;140:560-3.

${ }^{6}$ Scott GM, Stewart WE II, Tyrrell DAJ, Cantell K, Cartwright T, Edy VG. Skin reactions to interferon inoculations are reduced but no abolished by purification. Fournal of Interferon Research 1980;1:79-86.

7 Cantell K, Hirvonen S. Large-scale production of human leukocyte interferon containing $10^{8}$ units per $\mathrm{ml}$. $\mathcal{F}$ Gen Virol $1978 ; 39: 541-3$

${ }^{8}$ Secher DS, Burke DC. A monoclonal antibody for large-scale purification of human leukocyte interferon. Nature $1980 ; 285: 446-50$.

9 Atherton KT, Burke DC. Interferon induction by viruses and polynucleotides: a differential effect of camptothecin. $\mathcal{f}$ Gen Virol $1975 ; 29$ : 297-304.

${ }^{10}$ Hayes TG, Yip YK, Vilcek J. Le interferon production by human fibroblasts. Virology 1979;98:351-63.

(Accepted 23 February 1981)
ONE HUNDRED YEARS AGO Christina Marshall was born in the village of Chapelton, Lanarkshire, in the year 1867. While from her father she might have inherited a vigorous and robust constitution, by her mother she could fall heir at best to a system generally weakened, and probably specially tainted, from the fact that its development was coeval with that of pulmonary phthisis, which, six years later, deprived her of a maternal guardian. The family, of which she is the third youngest, consisted, when entire, of nine members. That number has been reduced by three deaths: one from scarlet fever and two from consumption. The remaining six, although by no means the hardiest, have not as yet shown any decided tendency to the development of the mother's fatal complaint; and, further, to those six our patient is decidedly the least strong. They have been provided for through the exertions of the father as a road surfaceman; and the result of the up-bringing has been comparatively favourable, alike mentally and bodily, in the case of Christina. As to her personal history, I am told that, when three years old, she was the subject of a rather peculiar ailment, which was shown chiefly in the development of a strong craving for sugar, and an equally strong aversion to all that had previously been her staple diet. This state of matters extended over three months, and, during this time, life was maintained by beef-tea. From the age of three onwards till last May, no incidents of her life are at present of much interest. She was often a little ill, seldom seriously; and her parents were never made cognisant of any distinct formation of tubercle in the lung or other organs. She had phlyctenular ophthalmia, which left much dimness of vision, and she was harassed with frequent and severe attacks of headache, probably gastric in their origin. Owing to these circumstances, her attendance at school was irregular; but the breaks were of short duration. She was an intelligent girl, was possessed of a disposition which was above the average in its liveliness, and was tempered with a quiet and becoming thoughtfulness, which at no time merited the term melancholy.

Exactly a year ago, she contracted a cold; and, this not seeming to leave her, I was asked to see her about the middle of July. I then found her suffering from bronchitis of a moderate type, and was led by the general symptoms and the local chest-examination to negative any idea of a phthisical element in the case. From this she recovered in the course of a week or ten days, to be immediately tortured with a headache, which has continued more or less ever since. During the autumn, she was able to be out a good deal, and, towards its end, a great change came over her disposition and general condition. She now seldom spoke, almost never except when questioned; and she uniformly maintained a sullen and morose cast of countenance. She became very averse to taking food, extremely constipated, and sleepless; and all those symptoms have since gone on more and more firmly establishing themselves as part of her existence. For some weeks previously to December, she went less out of-doors; on the 20th, she went out for the last time, and then only for a few minutes; and, on January 8th last, she lay down on the bed, which she has never since quitted. Eighteen weeks ago, she took a small piece of fruit-cake, and, since then, her parents distinctly assert that no food of any kind has passed into her stomach, and that all their most earnest entreaties to get her to take food have resulted in failure. She takes water freely and occasionally sweets; but of these only a few, and not by any means frequently; and, lastly, she herself distinctly asserts, when pressed to take nourishment, that she cannot swallow; she begins to cry, and becomes very excited. When deluded into taking a mouthful of water with a little milk in it, she instantly rejects it. When reminded that she will die, she answers that she has the inward feeling of approaching death, but that no efforts of hers are powerful enough to avert the sure though slowly approaching fate.

Present Condition.- - Her body is very emaciated, but free from bedsores; the complexion is very sallow, the lips pale and dry, the tongue clean and dry. The throat is abnormally high in colour, dry, and the situation of a choking sensation. Pulse 82 , regular, but very weak. On each cornea, there is an albugo. Headache is constant and severe. She has pain over the stomach and bowels, increased on pressure, and severe and continuous in character. The lungs are normal, if I except the slightest suspicion of dullness over the lef apex. She has no cough, and the heart's sounds are normal, but the impulse very weak. She occasionally vomits a glairy mucus; and, while the effort entailed leaves much weakness, it gives a transient relief to the gastric pain. The urine is scanty, pale, and deposits some urates, but is free from albumen. The bowels have not been moved for eleven weeks; and previously to that the intervals were five and six weeks. Then the motions were dark, scanty, and very hard. She is quite unable to leave her bed, which is in a small room, and so situated that it is impossible for her to reach any of the food-stores. Her parents have now ceased offering her anything beyond the water and sweets. The only persons who see her are the father and stepmother who alternately sit overnight with her; a sister and brother, respectively eleven and eight years old, who reside in the house; and three older ones, who visit her at longish intervals. When I have named these, and added the clergyman and myself, I have given everyone who has any regular communication with the room.

I have now followed this case carefully from the earliest years of the girl's life up to the present time. I have put on paper the results of my inquiries amongst the attendants, and added thereto my own medical examination of the case. I can vouch for the truth of none of the statements made to me by others; but I may fitly close this rather mysterious record by saying that $I$ have known the father and stepmother for six years, that they are in easy circumstances, that I believe the honesty and integrity of their characters to be above the faintest taint of suspicion, and that I have never, in all my connection with the district in which they reside, heard even the gentlest murmur of gossip pointing in the direction of latent channels of supply of food.

May $5 \mathrm{th}, 5 \mathrm{pm}$. I have just had word from Scotland that the girl Marshall is gradually losing strength, but is quite conscious. There is no other important change. (British Medical fournal, 1881.) 